\title{
SYNTHESIS AND CHARACTERIZATION OF ASYMMETRIC ULTRAFILTRATION MEMBRANE MADE WITH RECYCLED POLYSTYRENE FOAM AND DIFFERENT ADDITIVES.
}

\author{
RAUDEL RAMOS-OLMOS', EDUARDO ROGEL-HERNÁNDEZ ${ }^{A}$, LUCÍA Z.FLORES-LÓPEZB', SHUI WAI LIN" \\ AND HERIBERTO ESPINOZA-GÓMEZ *
}

\author{
(a) Facultad de Ciencias Químicas e Ingeniería de la Universidad Autónoma de Baja California. \\ Calzada Tecnológico 14418, C.P. 22390 Del. Mesa de Otay Tijuana, B.C. México \\ (b) Centro de Graduados del Instituto Tecnológico de Tijuana. Apdo. Postal 1166, Tijuana, B.C. México.
}

(Received: January 24, 2008 - Accepted: September 2, 2008)

\begin{abstract}
This paper reports the synthesis and characterization of asymmetric ultrafiltration membrane made from recycled polystyrene foam (PS) with different additives and polyvinylpyrrolidone (PVP). The polystyrene is currently employed as packing, in fabrication of glasses and dishes.

The recycled polystyrene is inexpensive and easy to acquire and, at less in Mexico, not a conscience exists of recycled. The membranes where prepared by phase inversion process from casting solution containing polystyrene as polymer, 1-methyl-2-pyrrolidone (NMP) as solvent, and polyethylene glycol (PEG) of different molecular weights and dioctyl phthalate (DOP) as additives. The membranes where characterized in terms of pure water permeation (PWP), molecular weight cut off (MWCO), flux and membrane morphology. The results revealed that the addition of PEG with high molecular weights, produce membrane with higher pure water permeation. The presence of additives affects the surface roughness and membrane morphology.
\end{abstract}

Keywords: PS-UF membrane, recycled PS, PS-additive membrane

\section{INTRODUCTION}

Since Loeb and Sourirajan first introduced the phase inversion method, tremendous amount of research have been performed to understand the mechanism of membrane formation. The common technique for the preparation of asymmetric ultrafiltration membranes is the phase inversion method. ${ }^{1}$ The production of asymmetric ultrafiltration membrane is very much influenced by many factors that include the four components, which are polymer, solvent, nonsolvent and additive. ${ }^{2}$ The presence of additive plays a crucial role in adjusting the membrane properties. The additives create a spongy membrane structure by prevention of macrovoids formation, enhance pore formation, improve pore interconnectivity and introduce hydrophylicity. ${ }^{3}$

Many researches have been done to investigate the effect of different types of additives on membrane morphology and performance. ${ }^{4-6}$

Kim and $\mathrm{Lee}^{7}$ investigated the effect of molecular weight of polyethylene glycol (PEG) on the formation of polyetherimide (PEI) asymmetric membrane; also they studied the use of PEG to control the thermodynamics and kinetics in casting system of polysulfone (PSf) membrane ${ }^{8}$ Liu, et al, ${ }^{3}$ used PEG as additive to enhance polyethersulfone (PES) hollow fiber. In all of these cases the PEG work as pore reducing or macrovoids suppressor, and give the membrane its hydrophilic character. Other studies revealed that the increase of the additive concentration has direct influence on the permeation flux and rejection rates.

By another hand, the polystyrene foam is utilized as packing and in the fabrication of products like glasses, dishes, and other disposable products. After to carry out a bibliographic research, itself has not been found that waste of polystyrene are utilized in the preparation of membranes. The waste of polystyrene foam, were employees just as were received, without determining the polymer molecular weight distribution, neither to give a cross linking processing prior to their dissolution, because we are focused in the recycled of this material. In Mexico, the average price for waste polystyrene is about 50 US cent per kilograme.

In this study we investigated the potential application of waste polystyrene to produce UF membrane, and the effect of different additives (PEG and DOP) on viscosity, pure water permeation, solute separation, flux and membrane morphology were investigated and discussed. The concentration and average molecular weight $(\mathrm{Mw})$ of PEG was also studied on PS ultrafiltration membranes performance by changing the concentration of PEG from 10 to 20 $\mathrm{wt} \%$ in the casting solution, and the average from $200 \mathrm{Da}$ to $600 \mathrm{Da}$. The DOP concentration was kept constant.

In addition the PS membrane with PEG of different molecular weights were characterized by using solute transport data where a sieving curve is obtained by plotting solute retention versus mass for each PS ultrafiltration membrane.

\section{Materials and Methods}

The Polystyrene foam was compiled from packing rejected and itself employment without prior processing. 1-methyl-2-pyrrolidone (NMP), dioctyl phthalate (DOP), and polyethylene glycols with molecular weights of 200,
400, and 600 Daltons where purchased from Fluka. Polyvinylpyrrolidone (PVP) $(90 \mathrm{kDa})$ from Solutia. Feed solutions were prepared using distilled water. Other chemicals used were lithium bromide (Fluka), Dextran T-70 (70 kDa) and Dextran T-500 (500 kDa) from Pharmacia; Dextrans of average molecular weights of 162 $\mathrm{kDa}$ and $298 \mathrm{kDa}$ from Sigma.

\section{Preparation of casting solution}

The castings solutions were prepared by dissolving a specific quantity in weight of polystyrene in NMP and stirred for several hours at room temperature. Then, additive was subsequently added with continuous stirring until the solution is completely dissolved and homogeneous. The resultant polymer solution was kept in a glass bottle and storage at room temperature to reduce the air bubbles in the casting solution.

The effect of the additives was investigated by preparing the various casting solutions. The compositions of the various casting solutions consisting of different PS:PVP:PEG relation are shown on Table 1. The viscosity of the different casting solution was measured using the Brookfield Viscometer at $25^{\circ} \mathrm{C}$.

Table 1. Composition of the PS-ultrafiltration membrane casting solutions and their viscosities.

\begin{tabular}{|c|c|c|c|}
\hline & \multicolumn{3}{|c|}{ Increasing the conterts of solids in the casting solution } \\
\hline 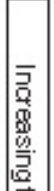 & $\begin{array}{l}a(w t \%) \\
P S=20 \% \\
P Y P=10 \% \\
\text { MPP }=58 \% \\
\text { DOP }=2 \% \\
P E G O D=10 \% \\
\text { iscosty } y(c p)=810\end{array}$ & 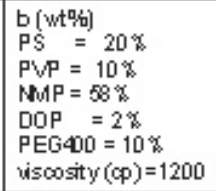 & $\begin{array}{l}\text { C (wt\%) } \\
P S=20 \% \\
P Y P=10 \% \\
\text { MPP }=58 \% \\
D O P=2 \% \\
P E G 600=10 \% \\
\text { issosity } y(c p)=1510\end{array}$ \\
\hline 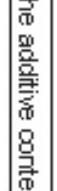 & $\begin{array}{l}d[w+\%) \\
P S=20 \% \\
P Y P=10 \% \\
\text { MPP }=53 \% \\
D O P=2 \% \\
P E G 40=15 \% \\
\text { iscosty } y(c p)=1100\end{array}$ & 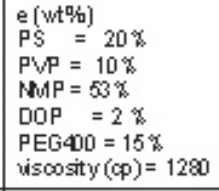 & $\begin{array}{l}f(w t \%) \\
P S=20 \% \\
P Y P=10 \% \\
M M P=53 \% \\
D O P=2 \% \\
P E G 40=15 \% \\
\text { viscosty }(c p)=1700\end{array}$ \\
\hline & $\begin{array}{l}g(w+\%) \\
P S=20 \% \\
P Y P=10 \% \\
M M P=48 \% \\
D O P=2 \% \\
P E G 600=20 \% \\
\text { iscosty } y(c p)=1340\end{array}$ & 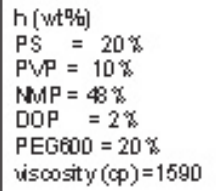 & $\begin{array}{l}\text { i (wt\%) } \\
P S=20 \% \\
P Y P=10 \% \\
\text { MPP }=48 \% \\
D O P=2 \% \\
P E G 600=20 \% \\
\text { viscosity }(c p)=2700\end{array}$ \\
\hline
\end{tabular}

Membrane fabrication via phase inversion process

The casting solution was poured onto a texlan fabric laid flat on a clean glass plate at room temperature, and it was casted on a glass plate using a casting knife, the casting knife gap was set at $152 \mu \mathrm{m}$ (6 mils). Immediately 
after casting, the glass plate with the casted film was dipped into distilled water at room temperature. Membrane casting speed was controlled by a D.C. motor and was set at $0.10 \mathrm{~m} / \mathrm{s}(20 \mathrm{ft} / \mathrm{min})$. Phase inversion process starts and after a few minutes a thin polymeric film supported on the texlan separated out from the glass. The membrane was washed with distilled water and kept in the water bath until if is ready for evaluation. All flat sheet membranes were visually inspected for defects and good areas were chosen for membrane evaluation.

\section{Ultrafiltration experiments}

Ultrafiltration experiments were performed using a cross flow test cell at $275.6 \mathrm{kPa}(40 \mathrm{psig})$ at $25^{\circ} \mathrm{C}$. Membrane sample with area of $2.212 \times 10^{-3} \mathrm{~m}^{2}$ was place in the test cell with the active skin layer facing the incoming feed. The membrane was tested for pure water permeability and A-Value $\left(\mathrm{Kg} /\left(\mathrm{Pa} \cdot \mathrm{m}^{2} \cdot \mathrm{s}\right)\right.$ experiments using distilled water

The water used for the molecular weight cut off (MWCO) determination, was purified using ion-exchange resin followed by distillation. Dextrans of average molecular weights of 70,162, 298, and $500 \mathrm{kDa}$ were employed. The dextran solution was prepared by dissolving each individual dextran in $0.10 \mathrm{M}$ $\mathrm{NaCl}$ solution buffered with phosphate at $\mathrm{pH} 7$.

The volume of permeate was collected at 6,12 and 16 min after the test run was started. The Refractive Index of permeate was determined 30 min after the permeate sample was collected. The content of the Dextran in the feed and in permeate was determined by an "Abbe-refractometer" $(0$ to $10 \%)$ at $25^{\circ} \mathrm{C}$ by measuring the Refractive Index of permeate and the feed against a blank and standard solution containing $0 \%$ and $1.0 \%$ dextran, respectively. The average MWCO of the test membrane is defined as the membrane sample having a $90 \%$ or better rejection of the dextran in the feed..$^{9-11}$

Membrane performance evaluation

Membrane characterization of pure water permeation (PWP) for the PS ultrafiltration membrane was calculated from the equation:

$$
P W P=\frac{Q}{A \cdot \Delta t}
$$

where $Q$ is volume of the permeate (L), $A$ is membrane surface area $\left(\mathrm{m}^{2}\right)$ and $\Delta t$ is permeation time (hour). The solute separation of the membrane was given by:

$$
R(\%)=\left[1-\left(\frac{C_{y}}{C_{f}}\right)\right] \cdot 100
$$

where $C_{p}$ is solute concentration in permeate stream and $C_{f}$ is solute concentration in feed stream. The flux $(J)$ in the presence of solute for the ultrafiltration membranes is obtained by:

$$
J=\frac{V}{A \cdot \Delta t}
$$

where $V$ is volume of permeate $(\mathrm{L}), A$ is membrane surface area $\left(\mathrm{m}^{2}\right)$ and $\Delta t$ is permeation time (hour).

Scanning Electron Microscopy (SEM) of PS/PVP ultrafiltration membranes

The cross-sectional morphologies of the membranes were sputter-coated with gold using a Technic's Hummer 5 sputter-coated with a current of $15 \mathrm{~mA}$ for $3.5 \mathrm{~min}$. The coated membranes were viewed with a JSM 5300 Scanning Electron Microscope, which was operated at an accelerating voltage of 10 $\mathrm{keV}$.

In order to preserve the original dimensions of the pore and the porous structure of the membrane, the remaining water in the membrane was removed by a "Solvent Exchange" process which was carried out in the following manner. The wet membrane coupon was first soaked in pure isopropyl alcohol for $30 \mathrm{~min}$; after that, the membrane coupon was subsequently soaked for $30 \mathrm{~min}$ in each isopropyl alcohol/hexane solution (75:25, 50:50 and 25:75). Finally the membrane was soaked in $100 \%$ Hexane for $30 \mathrm{~min}$. The hexane within the membrane was dried under vacuum. Sample membranes to be examined by SEM were cut out and fractured in liquid nitrogen. The dried fractured membrane samples were sputtered with gold, and then the crosssectional scanning electron micrograph of each membrane was recorded.
Atomic Force Microscopy (AFM) of PS ultrafiltration membranes

The surface morphology (3D topographic images) and roughness analysis of mean roughness $\left(R_{\mathrm{a}}\right)$, the root mean square of data $\left(\mathrm{R}_{\mathrm{r}}\right)$ and the mean difference in the high between the five highest peak and the five lowest valles $\left(\mathrm{R}_{\mathrm{y}}\right)$ for PS ultrafiltration with different additives were characterized by contact mode with a Burleigh II AFM, equipped with a non-contact/contact head and a $100 \mu$ scanner, which was operated at a constant force mode (reference force $5 \mathrm{nN}$ ). The wet membrane coupons were attached to a platinum sample holder that was mounted on the piezo scanner of the AFM. AFM images were acquired at a scan rate of $1.0-2.0 \mathrm{kHz}$ and at an information density of 256x256 pixels (area $2 \mathrm{~nm} \times 2 \mathrm{~nm}$ ).

\section{RESULTS}

Polymer solution properties

The experimental results indicate that the basic membrane characteristics depend on the composition of PS:PVP:PEG membrane casting solution. The trends of these changes are summarized in Table 2. It is observed that different molecular weight PEG has significant influence on viscosity of casting solution. Membrane casting solution with $20 \mathrm{wt} \%$ of PEG600, $10 \mathrm{wt} \%$ of PVP and $20 \mathrm{wt} \%$ of PS has the higher viscosity (higher solid content), while membrane casting solution with $10 \mathrm{wt} \%$ of PEG200, $10 \mathrm{wt} \%$ of PVP and 20 $\mathrm{wt} \%$ of PS has the lower viscosity (lower solid content). Membrane without DOP as additive was fragile and this condition did not change with PS:PVP: PEG wt $\%$ variations, the results of this group of membrane are not discussed on this paper.

Table 2. Membrane characterization parameters.

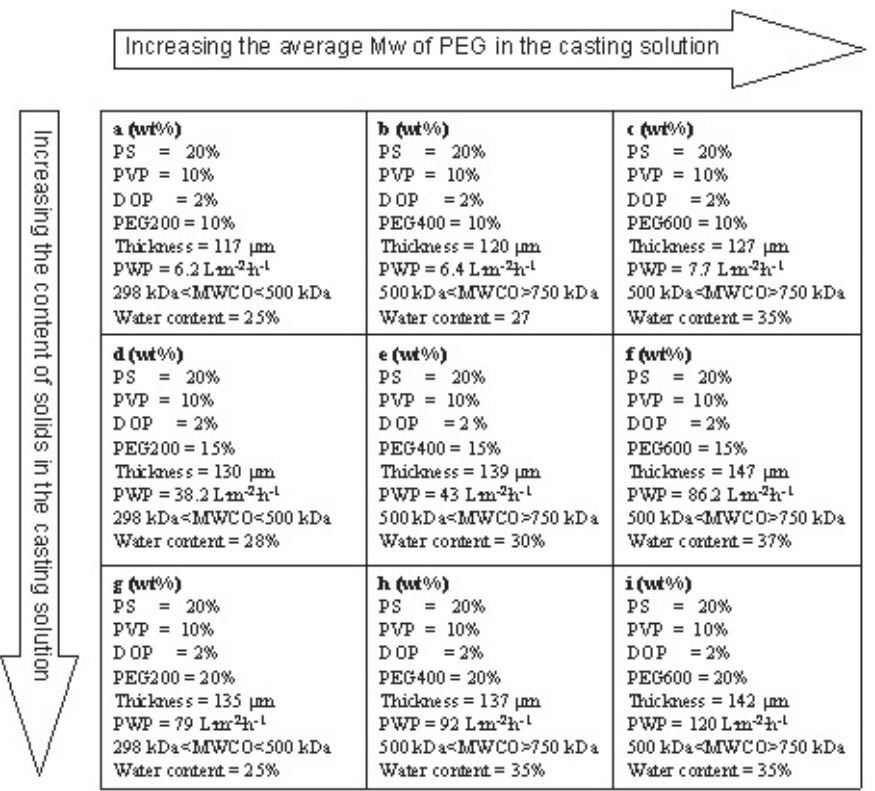

The viscosities are observed to increase with the presence of additives. Increase in the molecular weights of additives increased the viscosity of the casting formulations. Polymer solution with PEG $600(20 \mathrm{wt} \%)$ as additive has an almost one and half fold increase in viscosity compared to polymer solution with PEG $600(15 \mathrm{wt} \%)$ additive. The DOP is used as a plasticiers for ionophore membranes, while the PEG 600 was used as additive to enhance polymer dope viscosity in cellulose acetate blend ultrafiltration membranes ${ }^{12}$.

Pure water permeation

The PWP is significantly affected by molecular weight of PEG added to casting solution. Water permeability of PS membrane without additives was not measured because the fragility of the membrane obtained. The membrane added with PEG200 (10\%), exhibits a pure water permeability of $6.2 \mathrm{~L} \mathrm{~m}^{-2} \mathrm{~h}^{-1}$, while ultrafiltration membrane containing PEG400(10\%) and PEG600(10\%) $6.8 \mathrm{~L} \mathrm{~m}^{-2} \mathrm{~h}^{-1}$, and $7.7 \mathrm{~L} \mathrm{~m}^{-2} \cdot \mathrm{h}^{-1}$, respectively. Increasing the PEG molecular weight, in the membrane casting solution, produce membranes with higher water permeability. By another hand the membrane with PEG600(20\%) and DOP $(2 \%)$ exhibits the higher PWP of $120 \mathrm{~L} \mathrm{~m}^{-2} \mathrm{~h}^{-1}$ (Figure 1). Apparently the 
presence of additives on the casting solution, have an influence in the formation of pore size of the membranes. Ultrafiltration membrane permeability is conceptually related to its pores..$^{13}$

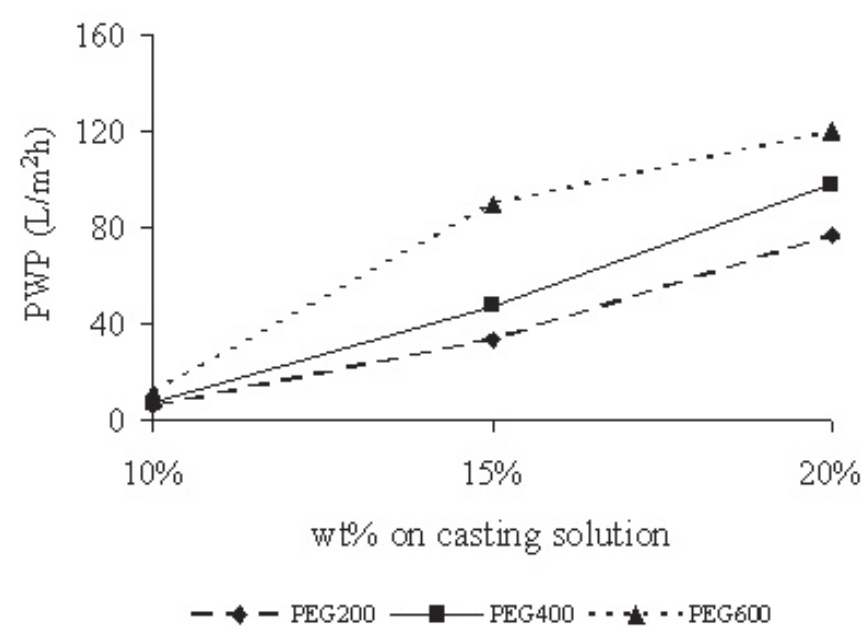

Figure 1. Pure water permeation for PS/PVP membranes with different PEG molecular weight and concentration (2wt $\%$ DOP:10 wt $\%$ PVP:20 wt $\%$ PS)

Molecular weight cut off results (MWCO)

By definition, molecular weight cut off is molecular weight that $90 \%$ rejected by the membrane., ${ }^{9,11,14,15}$ MWCO is a pore characteristic of the membrane and it is related to rejection for a given molecular weight of solutes. The molecular weight cut off has linear relationship with pore size of the membrane. ${ }^{16}$

It is observed (Figure 2) that PS/PVP ultrafiltration membranes with low PEG molecular weight exhibit a low MWCO. As it is to be expected, membranes with high pure water permeability, have a higher molecular weight cut off, due to that pores of smaller size they sit.

Microscopic morphology of PS/PVP ultrafiltration membrane

The scanning electron micrographs (SEM) of membrane cross-section are shown in Figure 3.

The SEM images of PS/PVP ultrafiltration membranes changed with concentration of additives. The SEM images indicated that the membranes have asymmetrical structure with a skin layer at the top, intermediate layer and a botton layer.

The morphology of the PS/PVP ultrafiltration membrane cross-section changed as the formation of macrovoids is influenced by the addition of additive. We can observe the increase of the voids size with the increase of the solid (Figure 3 (a), (d), (g)). If we increase the molecular weight of PEG, the macrovoids increases in size, and the asymmetric layer thickness increases too (Figure 3(d-f)). The solution with DOP and PEG produce membranes with a bottom layer with sponge like structure, very regular macrovoids and low asymmetry structure. Pure water permeation is strongly dependent on the top layer and sub-layer of the membranes. The thin asymmetric layer probably explains for the excellent improvement in the rejection rate but the thick spongy structure creates resistance thus resulting in rather low flux rates. As can be seen in Figure 3 (a)-(c), the size and shape of macrovoids are different. The size of voids gradually changed in structure from elongated microvoids to 'tear drop' shape.
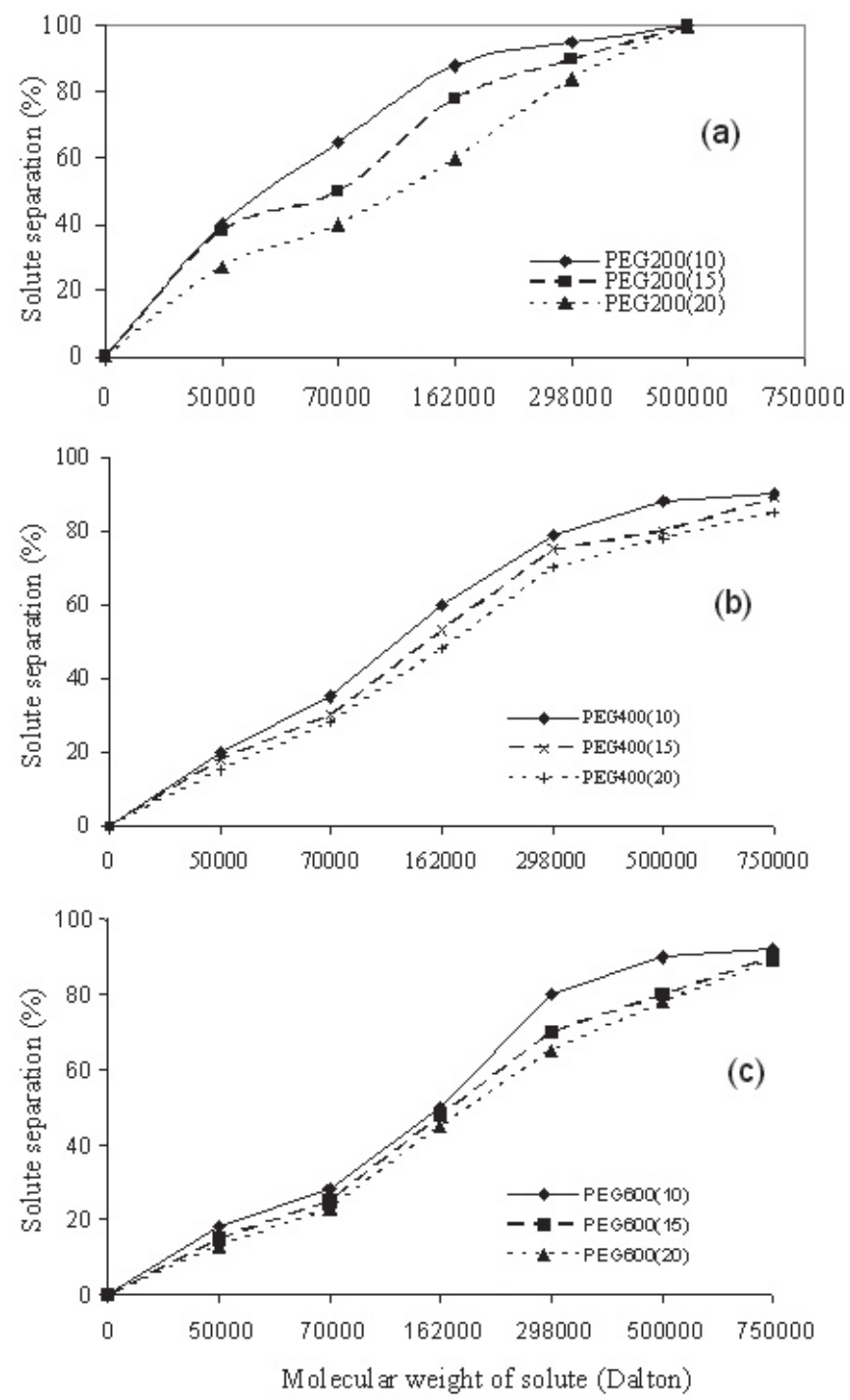

Figure 2. Molecular weight cut off profiles of PS/PVP ultrafiltration membranes with different molecular weight PEG and concentration.(a) PEG 200Da, (b) PEG 400Da, and (c) PEG 600Da 

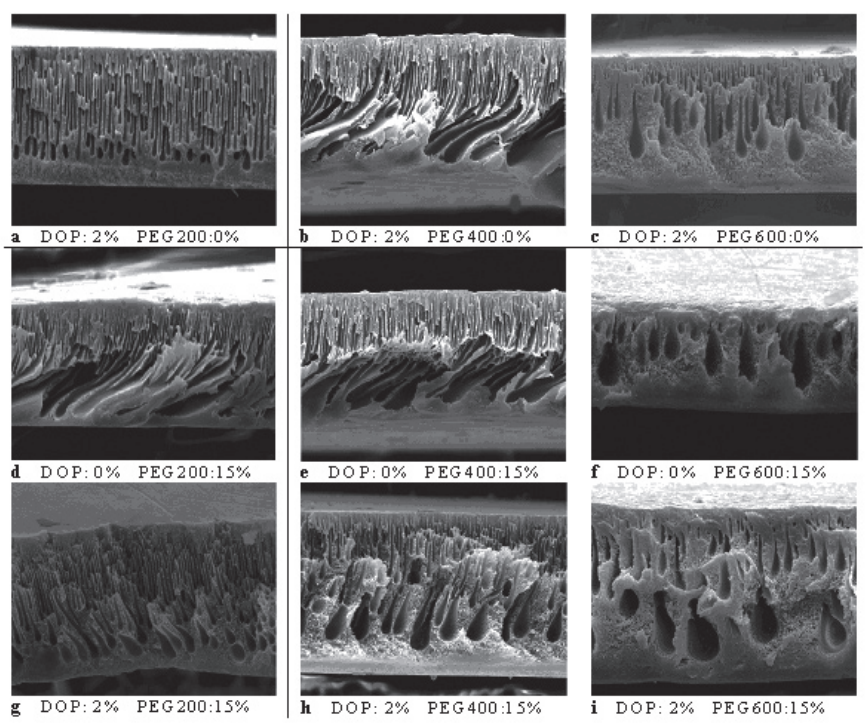

Figure 3. SEM photograph of the cross section of PS/PVP membranes.

Atomic force microscopy is a characterization technique, which presents very high possibilities of application in the field of microscopy observation and characterization of various surfaces., 2,14,17

Figure 4 shows the 3D AFM images of PS/PVP ultrafiltration membrane at a scan area of $(2 \mathrm{~nm} \times 2 \mathrm{~nm})$. The nodules are seen as bright high peaks whereas the pores are seen as dark depressions.

Figure 4 (a)-(c) clearly shows that the morphology of the membrane surface change with different molecular weights of PEG added. While the column of Figure 4 shows the effect of PEG concentration added into the casting solution.

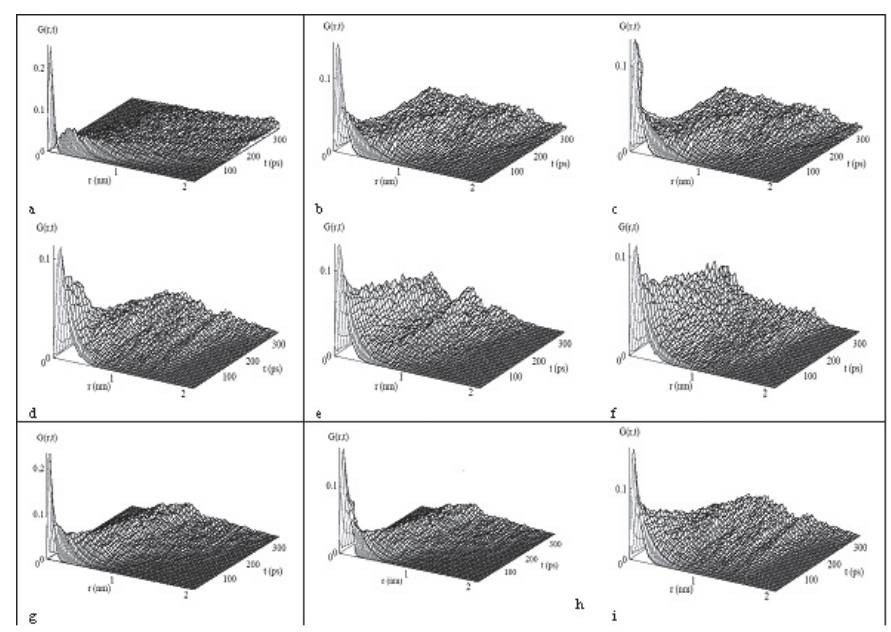

Figure 4. AFM of the PS/PVP membranes surface.

The roughness parameter of PS/PVP membrane decreased with addition of PEG200. This low molecular weight probably formed very tight nodules creating a very smooth surface indicated by low roughness parameter values. However, the roughness parameters increased with addition of PEG 400 and PEG 600 as additive. Apparently it can be observed that membrane with high surface roughness indicates high flux and membrane with smooth surface exhibits low flux.

\section{CONCLUSIONS}

The main of this work is to employ recycled polystyrene foam, without prior processing, for the elaboration of membranes. Nevertheless, the membranes manufactured with polystyrene recycled foam, without additives, they are rigid and with bad mechanical properties. By this reason was employed PVP like co-polymer, nevertheless, themselves did not improve the mechanical properties of the membranes. The addition of PEG and DOP, improved notably the mechanical properties of the membranes, besides modifying its structure.

In conclusion, the presence of PEG of different molecular weight and DOP as additive, exhibits significant effect on PS/PVP membrane performance. The presence of DOP in the casting solution, provide higher flexibility to the membrane. While the addition of different concentration of PEG as additives in casting solution improve the viscosity and influence the performance of pure water permeation rate. In determination of pore size of the membranes, it was found that ultrafiltration membrane with PEG200 as additive exhibits the lowest value of MWCO and mean pore size compared to other membranes. On the other hand, as concentration of PEG400 and PEG600 in the casting solution is increased, the flux is increased while the solute separation decreased.

The scanning electron micrographs indicate surface and membrane morphology changes with the addition of different molecular weight additives in casting solution. The addition of PEG with higher molecular weight in the casting solution increased the number and size of macrovoids while PEG with low molecular weight decreases the size of macrovoids in the intermediate layer. The AFM analysis revealed that higher molecular weight PEG additives exhibits higher roughness parameter compared to PEG200. The membrane roughness becomes rougher with increased molecular weight of additives.

\section{ACKNOWLEDGEMENTS}

The authors are grateful for the financial support provided by: Autonomous University of Baja California, through $10^{\mathrm{a}}$ Convocatoria Interna (Grant 3820), and CONACYT for one authors scholarship (RRO)

\section{REFERENCE}

1. L.R. Weatherley Engineering Processes for Bioseparation, ButterworthHeinemann, Northern Ireland. (1994)

2. A. Idris, N. Mat Zain, M.Y. Noordin, Desalination, 207, 324, (2007)

3. Y. Liu, G.H. Koops, H. Strathmann, J. Membrane Sci., 223, 187, (2003)

4. B.K. Chaturvedi, A.K. Ghosh, V. Ramachandran, M.K. Trivedi, M.S. Hanra, B.M. Misra, Desalination, 133, 31, (2001)

5. Z.L. Xu, F.A. Alsalhy, J. Membrane Sci,. 233, 101, (2004)

6. B.T. Sanchez, R.I. Ortiz-Basurto, E.B. Fuente, J. Membrane Sci., 152, 19, (1999)

7. I.C. Kim, K.H. Lee, J. Membrane Sci., 230, 183, (2004)

8. J.H. Kim, K.H. Lee, J. Membrane Sci., 138, 153, (1998)

9. A.Y. Tremblay, C.M. Tam, M.D. Guiver, Ind. Eng. Chem. Res., 31, 834, (1992)

10. M.N. Sarboulouki, Separ. Sci. Technol., 17, 381, (1982)

11. S.L. Flegler, J.W. Heckman, K.L. Kloparens Scanning and Transmission Electron Microscopy. An Introduction. USA (1993)

12. R. Mahendran, R. Malaysamy, D. Mohan, Eur Polym J., 40, 623, (2004)

13. D.B. Mosqueda-Jimenez, R.M. Narbaitz, T. Matsuura, G. Chowdhury, G. Pleizer, J.P. Santerre, J. Membrane Sci., 231, 209, (2004)

14. H. Espinoza-Gómez, S.W. Lin, Polym. Bull., 47, 297, (2001)

15. C. Causserand, P. Aimar, C. Vilani, T. Zambelli, J. Membrane Sci., 149, $485,(2002)$

16. K.Y. Wang, T. Matsuura, T.S. Chung, W.F. Guo, J. Membrane Sci., 240, 67, (2004)

17. N.A. Ochoa, P. Pradanos, L. Palacio, C. Paglearo, J. Marchese, A. Hernandez, J. Membrane Sci., 187, 227, (2004) 